Madrygal. Revista de Estudios Gallegos

ISSN: 1138-9664

\title{
Entrevista a Rosario Álvarez, presidenta do Consello da Cultura Galega
}

$\mathrm{M}^{\mathrm{a}}$ Isabel Gómez Rodríguez ${ }^{1}$

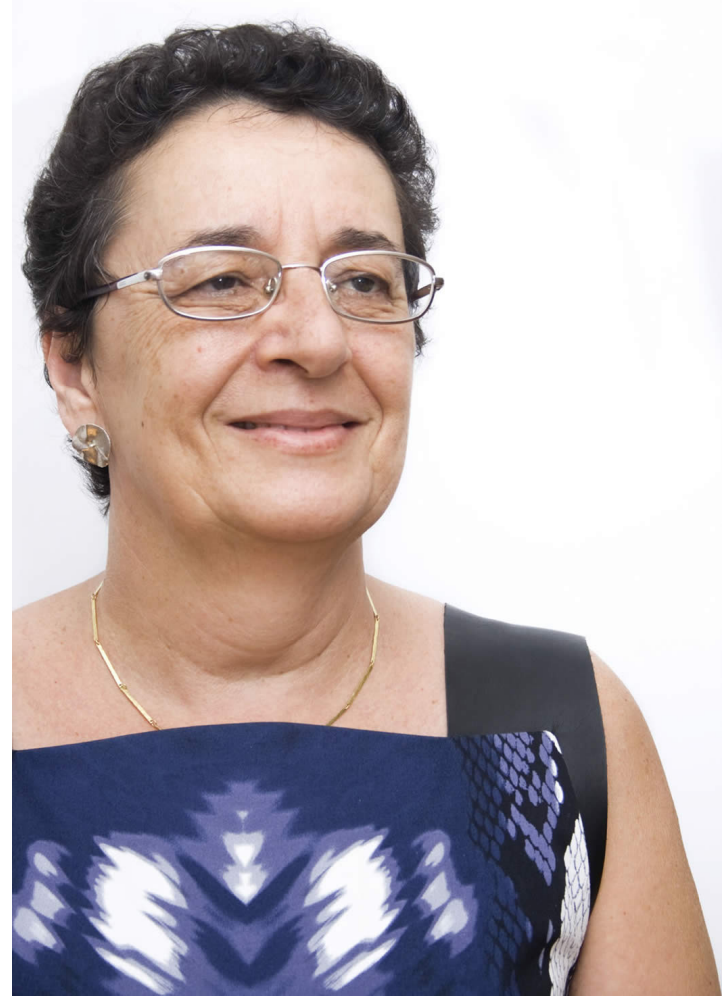

Connosco temos a Rosario Álvarez, pontevedresa, catedrática de Filoloxía Galega na Universidade de Santiago de Compostela e presidenta do Consello da Cultura Galega dende o ano 2018. Tamén foi directora do Instituto da Lingua Galega e é integrante da Real Academia Galega.

-Moitísimas grazas, Rosario, por concedernos a oportunidade de falar con vostede. Como se atopa?
Atópome ben, grazas. Polo de agora sen ser alcanzada polo Covid-19 e levando con bo ánimo esta situación anormal e difícil. Son eu quen agradece o voso interese.

- Poderíanos contar como foi este percorrido dende a Pontevedra dos anos 50 e a Facultade en Compostela ata ocupar hoxe a presidencia do órgano de cultura máis importante de Galicia?

Primeiro, estudando e satisfacendo a miña curiosidade intelectual, moi diversa, estimulada pola miña familia: a educación e a formación son as chaves que abren as portas, innumerables portas. Logo, seguindo unha vocación que, ademais, para a miña fortuna se aliou co meu compromiso cívico, a prol de Galicia, da nosa xente, da nosa identidade, da nosa cultura e da nosa lingua. E sempre desfrutando do meu traballo, das miñas diversas ocupacións e do trato humano nos varios equipos e circunstancias. É obvio que o camiño non o fixen soa: son impagables as débedas contraídas con incontables persoas que me trouxeron ata aquí.

-Nunha gravación publicada polo Consello da Cultura Galega, chamoume a atención que vostede se presenta, eminentemente, como profesora. Di que quere "coñecer para transmitir". Reflíctese ese carácter seu na xestión do Consello da Cultura Galega?

Supoño e espero que si. Todos somos, en maior ou menor grao, polifacéticos, pero polo xeral hai unha faceta que actúa como eixe vertebrador. En min creo que é a miña profunda vocación docente, que me explica como profesora e como investigadora, e creo que tamén

\footnotetext{
Universidad Complutense de Madrid. Departamento de Estudios Románicos, Franceses, Italianos y Traducción. Correo-e: mgomez16@ucm.es.

Créditos da imaxe: http://consellodacultura.gal/presidencia.php.
} 
como presidenta. E non porque pretenda ir dando leccións a ninguén, senón porque sigo atopando un aliciente no novo coñecemento, nos grandes e pequenos avances do saber, en todas as direccións; e ese querer ir sempre un pouco máis alá non ten sentido, para min, no propio deleite persoal, senón na posibilidade de poder compartilo, difundilo, transmitilo, en facelo colectivo, en convertelo nun chanzo máis para o progreso. De aí o de "coñecer para transmitir", pero non de forma estática, debe seguir a cadea. Por outra parte, ser profesora é a actividade que máis satisfaccións persoais me ten dado e na que sempre me sentín realizada. Entre as moitas débedas impagables a que me refería antes, están sempre presentes as debidas aos meus alumnos e alumnas.

-Verdadeiramente, un dos piares desta institución é a transmisión cultural. Que proxectos están a ter lugar agora no Consello de Cultura Galega? E que teñen proxectado facer nun futuro próximo? Cales son as iniciativas das que garda mellores lembranzas?

Necesitaría varias páxinas de Madrygal para dar resposta non pormenorizada a todas estas preguntas. Estamos a punto de rematar o ano 2020, no que conseguimos levar adiante unha programación intensa, en parte prevista, reconvertida desde o inicio do confinamento a formatos dixitais para os que non estaba pensada, e en parte improvisada ao fío dos acontecementos. Claro que o Consello da Cultura Galega tiña xa unha sólida base neste sentido, despois de dúas décadas de aposta forte pola innovación e a difusión a través do web institucional e do seu portal. Mesmo así, 2020 foi unha revolución nos formatos, que ademais nos permitiu chegar a novos públicos. $\mathrm{E}$, por suposto, intensificamos moito a nosa vertente de asesoría, cunha intensa actividade de elaboración de informes que seguen a dar cumprida información de como esta nova crise está afectando o ecosistema cultural galego, no seu conxunto e por sectores.

Colocándonos xa en 2021, hai catro liñas temáticas que o definen e que se estenderán ao longo do ano. Unha está dedicada á lingua, cultura e sociedade da Galicia medieval, en coincidencia co oitavo centenario de Afonso X e co Ano Santo compostelán; como contrapunto, outra atenderá á creación cultural contemporánea; outra liña, sempre presente, orientada á igualdade e inclusión, neste ano porá o foco especialmente no acceso á cultura no mundo rural; a cuarta está dedicada ás migracións e á interacción cultural.

Ademais, outras seis liñas de traballo, ao longo do ano, agrupan o labor ordinario do Consello da Cultura Galega, pola conservación e valorización do patrimonio (material e inmaterial); pola cultura científica, tecnolóxica e medioambiental; polo pensamento, atento aos debates do mundo contemporáneo; pola proxección exterior da cultura galega e a súa internacionalización; por manter viva a memoria dos que nos precederon e trouxeron ata aquí; pola preservación, dixitalización, arquivo e dispoñibilización de fondos.

-Outra afirmación que lle escoitara e que me espertou curiosidade é que defende que a súa tarefa, a transmisión da cultura galega, se realiza de forma independente do poder político. Ata que punto é isto posíbel? Non houbo ningún intento de politización do Consello ou das súas iniciativas?

O Consello da Cultura Galega é un órgano singular creado no Estatuto de Autonomía de Galicia para asistir á comunidade autónoma na defensa e promoción dos valores culturais do pobo galego. Naturalmente ten que ser independente do goberno. Os lexisladores encargáronse de garantir a pluralidade e a independencia.

O Plenario está constituído por 25 persoas, ningunha delas elixida polo goberno nin desde instancias políticas. Delas, 15 representan institucións relevantes, dunha relación establecida por lei; por caso, a Real Academia Galega, a Real Academia Galega de Ciencias, o Instituto da Lingua Galega, o Consello Galego de Museos, a universidade galega, a Consellería con competencias en materia de cultura, as fundacións Penzol, Rosalía e Barrié, etc. Todas elas elixen libremente representantes e iso dá xa unha notable dose de pluralidade. Outros 10 membros son personalidades escolleitas polo Plenario, no que a parte representativa sempre está en maioría. Todos os nomeamentos son temporais, ata un máximo de dous mandatos consecutivos (oito anos), pero hai unha renovación continua, de dous en dous anos, por quendas. O Plenario elixe o seu presidente ou presidenta, sen ningunha intervención do poder político.

-Boa parte do esforzo que se ten feito no ámbito cultural galego estivo durante moito tempo vencellado ao pasado e á tentativa de evitar que este se esvaeza. Penso, por exemplo, na forma de impartir o galego e a 
súa literatura nos centros educativos. Parece que dende hai uns anos a nova cultura, sexan ou non novas xeracións, ocupa un lugar cada vez maior no panorama creativo $\mathrm{e}$ académico galego. Como se contempla isto dende o Consello da Cultura Galega e que formas teñen de promocionar a actualidade cultural? E as novas xeracións?

Non me parece que esa sexa unha característica especial do ámbito cultural galego e moito menos no que se refire ao nivel educativo. Non se pode explicar o presente e concibir o futuro ignorando o pasado; e, ademais, os contidos curriculares baséanse no coñecemento do xa acontecido, non en futuribles. Dito iso, creo que a percepción de centrarse no pasado non é en absoluto válida para o Consello da Cultura Galega, que desde o seu nacemento apostou pola innovación e por ser un foro de encontro e debate, e de investigación, no que afrontar os problemas da cultura galega deste tempo e a súa proxección cara ao futuro. Calquera que visite o noso web http://consellodacultura.gal/ ou o noso portal http://culturagalega.gal/ poderá advertir non só a amplitude de intereses e enfoques con que entendemos o termo "cultura", senón o equilibrio entre as actividades de estudo, defensa, preservación, valorización e difusión do patrimonio cultural galego herdado, material e inmaterial, e as tendentes a cumprir co mandato fundacional de fomentar a cultura como un patrimonio que cada xeración ten a obriga de arrequentar.

\section{- Pensa que existe un panorama cultural e artístico vivo na Galiza?}

Sorpréndeme a pregunta. Non creo que sexa un asunto de opinión senón de evidencias. $\mathrm{O}$ talento e impulso creativos son patentes en múltiples campos, tamén entre as xeracións máis novas. Abonda con facer un repaso polos sectores da música, da poesía, da divulgación científica, do audiovisual, da banda deseñada, da moda, da gastronomía, do deseño, da industria editorial... Non estamos faltos de capital humano nin de xenialidade nin de compromiso coa cultura; si, en cambio, de maiores e mellores apoios para vencer esta ondada de crises, que sempre afectan á cultura máis ca a outros sectores.

- Tamén comentara en varias ocasións a súa vontade de levar a cultura galega máis aló das nosas fronteiras. Falou mesmo dun espazo transatlántico. Como se leva isto á práctica e que proxectos teñen para que estas ligazóns transoceánicas sexan posíbeis e se reforcen?

Neste ámbito hai dous aspectos a considerar. Estamos a traballar en ambos: con recursos moi limitados, mais non por iso desistimos. Un deles é a transterritorialidade do pobo galego, e polo tanto da nosa cultura. A atención á cultura galega das comunidades de emigrantes, nun camiño de ida e volta, foi unha liña de acción do Consello da Cultura Galega desde a súa creación. Aí están o noso Arquivo da Emigración Galega, como centro de referencia, e unha vía de acción permanente (xornadas, publicacións, exposicións, informes, preservación de fondos...). O outro é a proxección exterior, que tanto atende á difusión da cultura galega nos países de acollida dos emigrantes e exiliados galegos coma á que cómpre facer noutros nos que hai intereses estratéxicos ou cos que nos vinculan outras circunstancias; é o caso dos países do arco atlántico, dos de lingua portuguesa, dos vinculados polo Camiño de Santiago ou das nacións europeas sen estado.

-Dende o seu punto de vista, como ve a acollida da nosa cultura no exterior? Tanto en España como en Europa ou Latinoamérica.

Creo que en liñas xerais é unha descoñecida, sobre todo na súa realidade presente. Nalgúns países latinoamericanos predomina a imaxe da Galicia que deixaron atrás, hai máis dun século, as vagadas de emigrantes. Cando conseguimos que se acheguen á cultura galega, sorprende moi positivamente. Por iso hai que traballar nesa proxección exterior e acompañala de proxectos que axuden a internacionalizala.

-E que hai dos países lusofalantes? Cal é o traballo do Consello da Cultura Galega neste eido?

A relación cos países de lingua portuguesa é unha constante na programación co Consello da Cultura Galega, con actividades todos os anos. Ata agora estivo centrada en Portugal e no Brasil, en cooperación con institucións de ambos os dous países, mais estamos iniciando un proceso de ampliación a outros PALOP. Concrétase en ciclos de cinema compartidos, xornadas sobre temas de interese común, espazos de encontro entre profesionais (como Dramaturxias itinerantes), informes (p. ex., $O$ valor do portugués en Galicia, 2020), exposicións, epistolarios cruzados, etc. Desde 2016, o CCG é observador consultivo da CPLP (Comunidade dos Países de Língua Portuguesa) que, quizais conveña aclaralo, é un foro multilateral 
de cooperación constituído polos estados de lingua oficial portuguesa.

-E dentro de Galicia? Cre que hai verdadeiramente unha valorización interna do que se fai aquí?

O Consello da Cultura Galega está próximo a cumprir 40 anos e, mesmo así, é un órgano novo. Tamén un órgano singular, vinculado á autonomía de Galicia pero non ao seu goberno. Moitos galegos e galegas ignoran que existimos con personalidade propia e moitos outros non saben ben onde situarnos; outros tantos non saben separar que é obra da actividade do CCG e que doutras instancias públicas; non faltan os que confunden Consello con Consellería. Se cadra deberiamos dedicar máis tempo a explicar e difundir a propia institución, pero sempre estamos máis urxidos pola Cultura Galega que polo Consello. Dito isto, a percepción que temos é que os que coñecen o CCG valoran positivamente o seu labor e que o coñecemento e recoñecemento aumentou de xeito notable nos últimos tempos, en boa medida debido á pandemia. Creo que o esforzo por chegarmos con novos formatos a novos públicos se viu acrecentado en tempos de confinamento; ademais, boa parte do sector cultural sentiuse acompañado polo labor vixiante do Observatorio da Cultura Galega do CCG, atento semana tras semana a cada dato que permitise poñer cifras ao desastre que estaba a padecer ou, se fose o caso, aos indicios de mellora.

-Boa parte desas conexións que trazan dende o Consello da Cultura Galega para fóra das nosas fronteiras teñen que ver con esa Galicia exterior, espallada, froito da migración. Coido que é incuestionábel que o exilio forma parte da identidade galega. Como difundir e por que é tan necesario?

Creo que en parte xa respondín anteriormente. En todo caso, nós non distinguimos entre exilio e emigración, e estamos atentos tanto aos vellos fenómenos migratorios coma ás novas diásporas.

A creación cultural dos nosos emigrantes forma parte da cultura galega. É tamén patrimonio noso que debemos defender e valorizar alí onde se atope. Pero ademais, cremos que Galicia ten a obriga de poñer en valor a contribución dos nosos migrantes: facelo, por suposto, na propia terra, non só recoñecendo a importancia dos seus retornos en forma de diñeiro e de progreso, senón mostrando a importante pegada que deixaron alí onde andaron; e facelo, tamén, nos países de acollida, reivindicando que os galegos e galegas tamén forman parte da súa historia e da súa realidade presente. Por iso levamos moitos anos avogando pola posta en marcha, en Galicia, como proxecto de país, dun gran museo e centro de documentación e estudo sobre a emigración galega no mundo. En 2019 presentamos formalmente o informe Diásporas. Museo da Emigración Galega, que esperamos ver algún día feito realidade.

-Na páxina web do Consello da Cultura Galega existe un importante Arquivo da Emigración que reúne libros descargábeis, diverso material audiovisual e bibliográfico, noticias, investigacións e eventos. Entre moitos outros materiais, os e as lectoras podemos acceder a un repertorio da prensa da emigración con máis de $\mathbf{7 5 0}$ referencias hemerográficas ou a un considerábel patrimonio fotográfico e documental baixo o lema Historias de ida e volta, no que atopamos tanto relatos da partida como información relativa ao Centro Galego da Habana. O Arquivo da Emigración Galega nútrese, ademais, dunha vasta biblioteca e dun corpo de proxectos de investigación multidisciplinar dende o que se traballa na recuperación de fondos documentais, material bibliográfico, prensa ou cultura popular, entre outros temas. En definitiva, dende o Consello da Cultura Galega dan acceso a un arquivo do máis rico e variado no que conflúen xa moitos anos de traballo. Poderíanos falar algo máis deste proxecto e sobre como funciona?

Unha das encargas feitas ao CCG é a de atender á preservación, estudo, valorización e difusión do patrimonio cultural galego. Unha das múltiples vías de actuación previstas para estes fins foi a de crear arquivos ou centros de documentación, que na nosa concepción non debían ser só receptores e gardiáns celosos do patrimonio, senón activos no seu estudo, aproveitamento e difusión. Creáronse catro, que son referentes indiscutibles no seus respectivos campos: o Arquivo da Emigración Galega, o Arquivo Sonoro de Galicia, o Centro de Documentación Sociolingüística de Galicia e o Centro de Documentación en Igualdade e Feminismos. Convido a todos os lectores e lectoras a entraren en cada un deles, a través do noso web, e pasearen entre esas Historias de ida e volta, os fondos hemerográficos de cada un, o Álbum de mulleres, a actualización dos recursos lingüísticos, as nosas coleccións sonoras... 
Á parte está o noso catálogo de publicacións, con máis de 400 títulos descargables gratuitamente. Por certo, o último a día de hoxe é o Fardel de eisilado de Luís Seoane, en edición facsimilar, con estudo introdutorio de Gregorio Ferreiro Fente; non é o único deste mes de decembro nin será o derradeiro de 2020.

-Cada exilio é único, tanto a nivel individual como social. En determinadas épocas, o dos galegos viuse motivado pola economía e o traballo. Parece que isto hoxe se está a repetir, ou se cadra nunca se deixou de dar ese mesmo patrón. No mundo cultural e artístico continúa a existir esa idea de que é fóra onde están as oportunidades. Por que pensa que pasa isto? Que pode facerse dende o mundo cultural para evitar esta marcha? Como crear enclaves de traballo e creación atractivos para a xuventude?

Este é o fenómeno das novas diásporas a que me refería antes, unha forma máis de emigración. A diferenza entre esta onda migratoria e as anteriores é que agora afecta tamén, e con moito impacto, a persoas novas que confiaban en que pola vía do estudo e da formación poderían conseguir realizarse e obter recursos suficientes para vivir nun confort e seguridade razoables na súa terra; ademais afecta aos fillos e fillas de todas as clases sociais e a todas as contornas, urbanas e rurais. Persoas formadas, con inquedanzas e talento, con lexítimas aspiracións frustradas, nas que ademais se realizou un investimento social...: unha sangría de recursos humanos que non nos podemos permitir. Pero, insisto, a falta de oportunidades laborais en Galicia afecta a un amplo espectro de homes e mulleres novos, non só a posibles axentes culturais, así que o problema estrutural é moito máis amplo e máis grave.

En todo caso, e sen conformarse co paliativo, a revolución tecnolóxica facilita a creación e a difusión desde calquera punto, e tampouco a mobilidade (fóra tempos de pandemia!) ten as dificultades de outrora. Á cultura galega pódese contribuír desde New York ou desde Vilariño de Conso. O malo é a perda de consistencia e cohesión no tecido sociocultural e, sobre todo, os talentos que se perden polo camiño para a nosa cultura.

—Dende o Consello da Cultura Galega non só se atende á emigración, ás saídas, aos que marchan. $O$ último Encontro pola Normalización Lingüística de Galicia centrouse na integración lingüística como canle para a cohesión social e o encaixe dos inmigrantes chegados a Galicia. Poderíanos falar deste encontro? Como pode axudar o galego e a nosa cultura ao problema da migración actual?

Unha das características da sociedade galega, e por tanto da súa cultura, é o seu carácter inclusivo, integrador. Nos XXII Encontros pola Normalización Lingüística quixemos poñer o acento sobre algo para nós incuestionable: o feito de que a integración lingüística é un factor indispensable para a cohesión social. A temática convócanos tanto desde o ámbito da sociolingüística coma do da igualdade e inclusión, dos dereitos, en definitiva. Pensabamos en todas as persoas non galegofalantes de orixe, entre as que se encontran diversos colectivos migrantes, pero non só. Quixemos coñecer a situación - na voz de estudosos, de protagonistas e de mediadores-e mais avaliar os recursos, medios e vías dispoñibles para o acollemento e integración nunha sociedade con lingua propia. Como é práctica habitual no CCG, os vídeos e debates, tamén as conclusións, son públicos e quedan recollidos no noso web, en acceso libre (http://consellodacultura.gal/evento.php?id=200981).

-Un fenómeno altamente preocupante na actualidade galega son eses abismos existentes entre o mundo rural e urbano, o eixe Atlántico e o interior. Como superar isto dende o ámbito cultural? Ou dito doutro xeito, como acadar unha igualdade no acceso á información e á cultura a este nivel?

Precisamente esas son dúas liñas temáticas previstas para o próximo bienio, no ámbito da igualdade e inclusión. A cultura é un dereito, polo tanto debemos procurar que nada atranque o acceso a ela. Como dixen antes, en 2021 poremos o acento no hábitat, sobre todo rural/ urbano, desde diferentes perspectivas, entre as que non faltarán nin a sostibilidade da cultura no medio rural nin as novas formas de ruralidade, con repercusións lingüísticas e culturais. No ano 2022 centrarémonos no territorio, precisamente nese paso desacompasado entre o eixe atlántico e o resto de Galicia.

- Como ve o panorama cultural a partir de agora? Ve un antes e un despois, ou unha continuidade?

Se facemos balance de 2020, xa é indispensable falar de antes e despois do 15 de marzo. Hai hábitos que mudaron, procesos que se aceleraron, territorios que se exploraron, formatos 
que se divulgaron... A volta á normalidade poderá revertelos nalgún grao, pero non o fará de todo. En certo modo, a necesidade de reacción en tempos de pandemia acelerou procesos que se acabarían por producir dun xeito máis programado e a un ritmo máis pausado se non houbese esa urxencia. Por iso creo que si, que hai un antes e un despois, pero non drástico nin revolucionario.

—En todos os ámbitos, pero especialmente no cultural, o illamento social obrigatorio pisou o acelerador da dixitalización. Cre que na cultura galega existía unha forte oferta cultural a nivel dixital antes disto? Pensa que se está a dar ese salto?

Precisamente nestes días publicamos un novo informe do Observatorio da Cultura Galega sobre a Influencia da COVID-19 nos hábitos culturais da poboación galega. Os interesados e interesadas poden encontrar alí datos e respostas de como o illamento afectou neste sentido.

Respondendo á pregunta, creo que na cultura galega o balance de oferta dixital é moi desigual segundo as áreas; e que, en conxunto, tendo en conta a dimensión do país, hai unha oferta non pequena, pero mellorable. Hai que recoñecer, tamén, que durante o confinamento, ademais dos esforzos institucionais, múltiples e variados, houbo unha resposta social, coral, moi creativa, moi vizosa e moi esperanzadora.

-O Consello da Cultura Galega ten unha páxina web moi completa. Pódense atopar dende eventos ata noticias, artigos e un fondo de materiais do máis rico. Mesmo se fixeron unha serie de diálogos confinados co obxectivo de levar a cultura á casa. Poderíanos comentar como é e que ofrece o Consello da Cultura Galega na rede, e se está a levar a cabo algún proxecto a nivel dixital? Cre vostede que vai permanecer esta forma de acceso á cultura cando poidamos volver á normalidade?

O noso web non é consecuencia da pandemia, ben se ve. Levamos décadas apostando por esa vía, e sempre tentando ir un pouco máis alá tanto nos contidos coma na innovación. Agora mesmo estamos en proceso de mudanza, silandeira, sen que nos obrigue a un peche por reformas. Todas as nosas actividades, na medida do posible, están no web, tamén as concibidas como presenciais: retransmítense en directo, grávanse, almacénanse e quedan accesibles no web, de modo que conferencias, mesas redondas, foros de debate, simposios..., poden consultarse de xeito permanente en formato audiovisual. O web ofrece tamén as nosas publicacións, os informes, os especiais conmemorativos, a visualización das nosas exposicións, o acceso aos nosos fondos (hemerográficos, epistolares, fotográficos, sonoros...), etc.; e contén unha gran variedade de recursos divulgativos (como os roteiros pola cultura galega, o mapa sonoro de Galicia, o kit de normalización lingüística... ou a sección "Coñece a cultura galega"), así como o acceso a culturagalega.gal, unha vía de comunicación cultural. Por suposto, o web tamén permite adentrarse no coñecemento da institución, dos seus fins e competencias, do seu organigrama, das persoas que forman parte dos distintos órganos, etc.

-Antes que presidenta do Consello da Cultura Galega e aínda antes de ser profesora na Universidade de Santiago de Compostela, é filóloga. A situación da nosa lingua pódese chegar a ver con preocupación, tendo en conta a involución no número de falantes e máis aínda na xente nova e nos núcleos urbanos. Dende a súa formación, cal é o seu punto de vista sobre esta realidade? $E$ que se pode facer dende o ámbito cultural para revertir este devir?

O feito de ser filóloga non me converte nunha profesional con opinión autorizada en materia sociolingüística. Podo dicir que todos os estudos e informes realizados desde o Seminario de Sociolingüística da Real Academia Galega e desde o Observatorio da Cultura Galega do CCG son concorrentes e concluíntes en termos negativos, sobre todo no sentido da perda de transmisión xeracional. Contribúen decisivamente a falta de espazos de socialización en lingua galega na infancia e mocidade, e que o ensino non contrarreste a perda (nalgúns ámbitos incluso a estimula). Non é que abandonen os mozos motu proprio: son excluídos da comunidade galegofalante, polos adultos, na infancia, cando non teñen capacidade de decidir. Cómpren accións adecuadas de política lingüística, concibidas e aplicadas por especialistas na materia.

-Ademais de filóloga e profesora, é muller. Éo tamén na Real Academia Galega e na presidencia do Consello da Cultura Galega. Vivimos nesta época unha clara globalización do feminismo, unha onda que semella medrar con máis forza a cada vagada. Xoga algún papel o feito de ser muller na súa xestión do Consello da Cultura Galega? 
Eu non deixo de porta para fóra ningunha das facetas da miña personalidade, aínda que loxicamente procuro que inflúan máis as miñas virtudes que os meus defectos. Ser muller, vivir como muller e ver o mundo con ollos de muller imprimen unha gran diferenza, non? Espero que si, que se perciba esa condición, aínda que eu non o faga á mantenta. Si é propositada, en cambio, a atención permanente á igualdade e á non exclusión, por razóns de xénero e doutros tipos.

- Puiden ver que dende o Consello da Cultura se están a facer esforzos na loita pola visibilización do traballo cultural das mulleres. Sen ir máis lonxe, inclúese un cumprido corpus de mulleres creadoras na rede e hai un album de mulleres de Galicia. Poderíanos falar das iniciativas do Consello da Cultura Galega en prol da igualdade de xénero?

Recomendaría unha visita demorada, ou moitas visitas espazadas, todas virtuais, ao noso CDIF (Centro de documentación en igualdade en feminismos). O Álbum de mulleres é unha parte esencial, para nós moi querida, deste centro: creo que é único no seu xénero. O proxecto A Saia, que toma dunha revista feminista pioneira en Galicia, vai poñendo a disposición pública un repertorio hemerográfico de interese para as persoas interesadas nos movementos feministas e LGTBIQ+ na Galicia contemporánea. Son só dous botóns de mostra para animar a esa visita.

A programación anual do CCG está toda ela atravesada pola presenza feminina, a procura da igualdade e vontade de visibilización do traballo das mulleres, en todos os campos e en todos os tempos. Saliento, con todo, como actividades anuais fixas, o ciclo de cinema Olladas de muller, o ciclo de cinema galego-portugués Mulleres, patrimonios, sociedade, as xornadas Novas violencias de xénero ou as Cartografías que acompañan a xornada con que se homenaxea unha muller viva que destacase nun ámbito artístico, científico ou profesional. Logo, cada ano ten as súas particularidades: en 2020, por exemplo, estivemos moi entregados a Concepción Arenal, de principio a fin; e en 2021 están programados un monográfico documental sobre mulleres na cadea (aínda en honra de Concepción Arenal), xornadas sobre ecofeminismo e outras actividades.

Diría, ademais, que o feito estar presidido por unha muller non é froito do acaso nin unha anécdota. Creo que se encadra dentro da normalidade, unha vez que o CCG comezou hai xa bastantes anos, e sobre todo durante a presidencia de Ramón Villares, a camiñar con paso firme cara á igualdade.

-Xa para finalizar, todos os temas desta entrevista poderíanse incluír nunha gran pregunta: a relación entre a cultura e a lingua e a identidade. Cales son as súas consideracións sobre este vínculo?

Dirían os homes de Nós, que homenaxeamos hogano, que velaí está o noso feito diferencial: unha lingua e unha cultura con trazos propios que nos vencellan cunha tradición secular, anovada en cada xeración. Esa é a base da nosa identidade. Respectuosos coa obriga de coidar e arrequentar o patrimonio herdado, e ao mesmo tempo abertos e cosmopolitas.

Ata aquí a entrevista. Moitas grazas, Rosario, polo seu tempo e a súa sabedoría. Tamén por todo o traballo que está a facer polo noso patrimonio cultural. 
